\title{
Influence of European, Japan and Singapore's Exchange Rate Volatility in Asian Exchange Rate Market: Empirical Study of Taiwan Market
}

\author{
CHING-HUEI CHEN \\ Department of Hospital and Health Care Administration, Chia Nan University of Pharmacy \& Science, \\ No. 60, Erh-Jen Rd., Sec.1, Jen-Te, Tainan, 71710, Taiwan. \\ Email: wilsonchen0831@yahoo.com.tw \\ Tel:+886-6-2664911-5208 \\ WANN-JYI HORNG \\ Department of Hospital and Health Care Administration, Chia Nan University of Pharmacy \& Science, \\ No. 60, Erh-Jen Rd., Sec.1, Jen-Te, Tainan, 71710, Taiwan. \\ Email: hwj7902@mail.cnu.edu.tw \\ Tel:+886-6-2664911-5220
}

\begin{abstract}
The purpose of this research was to evaluate the influence of European, Japanese and Singapore's exchange rate volatility on Taiwan market. For this purpose, data of exchange rate prices from 2006-2014 was collected from Taiwan's market. The empirical results show that the AIGARCH $(1,1)$ model is appropriate in evaluating the volatility model of Taiwan's exchange rate market. The empirical result also indicates that Taiwan's exchange rate market has an asymmetrical effect. The exchange rate volatility of the Taiwan exchange rate market receives the influence of the good and bad news of the European, Japan, and the Singapore exchange rate markets. For example, under the REUER $>0$ (good news), the RJER $>0$ (good news) and RSIER $\leq 0$ (bad news), the variation risk of the Taiwan exchange rate market is the highest $\left(\beta_{51}=0.8878\right)$. Under the REUER $>0$ (good news), the $R J E R_{t} \leq 0$ (bad news) and RSIER $>0$ (good news), the variation risk of the Taiwan exchange rate market is the lowest $\left(\beta_{61}=0.4380\right)$.
\end{abstract}

Keywords: Exchange Rate Market, Volatility Rate, Asymmetric Effect, IGARCH Model, AIGARCH Model.

\section{Introduction}

We know that Taiwan economical physique belongs to an island economy. We also know that Taiwan is one of Asian four dragons, also Taiwan economy of growth in 2010 is $10.72 \%$, and the forecast value of the growth rate is $3.5 \%$ in 2012 . Taiwan has a close relationship with Japan based on the trade and the circulation of capital, and Japan is the most powerful global economic nation in the Asian. Besides, Taiwan and Singapore have a close relationship based on the trade and the circulation of capital. When the investor has an investment in the international exchange rate market, he/she will usually care about the international capital the motion situation, the international politics and the economic situation change, in particular, in the European, Japan, and the Singapore exchange rate markets' change. There is a close relationship between Taiwan and Japan based on the trade and the circulation of capital with the Singapore and the European, but the Singapore, Japan, and European are also powerful global economical areas. Therefore, the volatility 
model of the Taiwan exchange rate market is worth further discussion with the factors of European, Japan, and Singapore's exchange rate markets.

The purpose of the present paper is to examine the volatility model of Taiwan's exchange rate market. This paper also further discusses the effect of the European, Japan and the Singapore exchange rates' volatility rate for the Taiwan exchange rate market volatilities. And the positive and negative values of European, Japan and Singapore exchange rates' volatility are used as the threshold. The organization of this paper is as follows: Section 2 describes the data characteristics; Section 3 presents the proposed model; Section 4 presents the empirical results; Section 5 introduces the asymmetric test of the proposed model, and finally Section 6 summarizes the conclusions of this study.

\section{Data Characteristics}

\section{Data Sources}

The research sample period was from January 2006 to December 2014, and the material origin take from DataStream, a database in Taiwan. Among them, Taiwan's exchange rate price is the exchange rate of Taiwan New to the US in New York market, the European's exchange rate price is the exchange rate of Euro to the US in the New York market. Japan's exchange rate price is the exchange rate of Japanese Yen to the US in the New York market. The Singapore's exchange rate price is the exchange rate of Singapore to the US in the New York market. In the data processing aspect, the markets do not do business on respective Taiwan's holidays; therefore when a exchange rate market is closed, this article deletes the identical time exchange rate price material and conforms to the other exchange rate market's common trading day; therefore four variable samples after processing each will be 2347 from now on.

\section{Return Calculation and Basic Statistics}

To compute the volatility rate of the Taiwan exchange rate market adopts the natural logarithm difference, rides 100 again. The volatility rate of the European exchange rate market also adopts the natural logarithm difference, rides 100 again. The volatility rate of the Japan and Singapore exchange rate markets also adopts the natural logarithm difference, rides 100 again. In Figure 1, Taiwan, the European, Japan, and the Singapore exchange rate volatility rates show the clustering phenomenon, so that we may know the four exchange rate markets have a certain relevance.
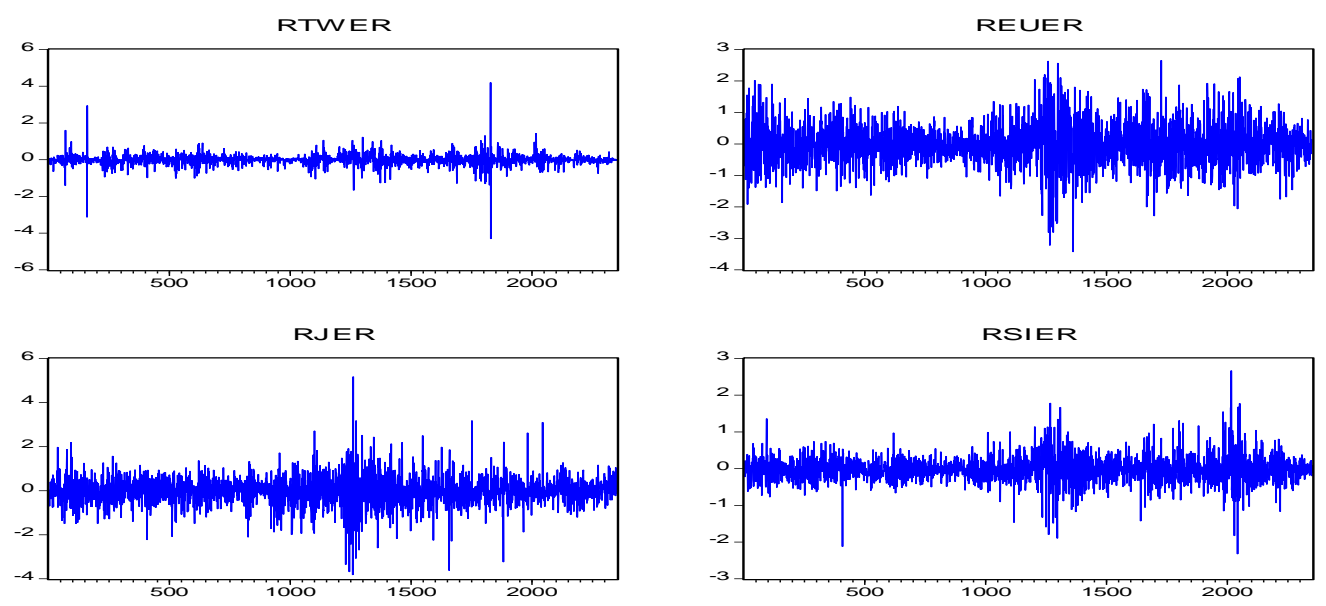

Figure 1. Trend charts of Taiwan, the European, Japan, and the Singapore exchange rate market volatility rates. 
Table 1 presents the four sequences kurtosis coefficients are all bigger than 3 , which this result implies that the normal distribution test of Jarque-Bera is not a normal distribution. Therefore, the heavy tails distribution is used in this paper. And the four exchange rate markets do have a high correlation in Table 2.

Table 1. Data statistics

\begin{tabular}{|c|c|c|c|c|}
\hline Statistics & RTWER & REUER & RJER & RSIER \\
\hline Mean & -0.006693 & -0.002003 & -0.009025 & -0.014051 \\
\hline S-D & 0.314849 & 0.661663 & 0.664103 & 0.359548 \\
\hline Skew & -0.292892 & -0.035609 & -0.094971 & 0.135848 \\
\hline Kurtosis & 40.03323 & 4.679542 & 7.735675 & 8.393482 \\
\hline $\begin{array}{l}\text { J-B N } \\
\text { (p-value) }\end{array}$ & $\begin{array}{c}134150.90^{* * *} \\
(0.0000)\end{array}$ & $\begin{array}{l}276.35^{* * * *} \\
(0.0000)\end{array}$ & $\begin{array}{c}2196.66^{* * * *} \\
(0.0000)\end{array}$ & $\begin{array}{c}2851.94^{* * * *} \\
(0.0000)\end{array}$ \\
\hline Sample & 2347 & 2347 & 2347 & 2347 \\
\hline
\end{tabular}

(1) Notes: (1) J-B N is the normal distribution test of Jarque-Bera.

(2) S-D is denoted the standard deviation. (3) ${ }^{* * * *}$ denote significance at the level $1 \%$.

Table 2. Unconditional correlation coefficient

\begin{tabular}{ccccc}
\hline Coefficient & TWER & EUER & JER & SIER \\
\hline TWER & 1 & 0.3402 & 0.7093 & 0.8102 \\
EUER & 0.3402 & 1 & 0.2332 & 0.5354 \\
JER & 0.7093 & 0.2332 & 1 & 0.8162 \\
SIER & 0.8102 & 0.5354 & 0.8162 & 1 \\
\hline
\end{tabular}

\section{Unit root and cointegration tests}

This paper further uses the unit root tests of ADF (Dickey and Fuller, 1979 and 1981) and KSS (Kapetanios et. Al., 2003) to determine the stability of the time series data. The ADF and KSS examination results are listed in Table 3. It shows that the Taiwan exchange rate volatility rates, the European exchange rate volatility rates, the Japan exchange rate volatility rates, and the Singapore exchange rate volatility rates do not have the unit root characteristic, this is, the four markets are stationary series data, under $\alpha=1 \%$ significance level. Using Johansen's (1991) co-integration test as illustrated in Table 4 at the significance level of $0.05(\alpha=5 \%)$ does not reveal of $\lambda_{\max }$ the statistic. This indicated that the Taiwan exchange rate volatility rate does not have a co-integration relation. Therefore, we do not need to consider the model of error correction.

\section{ARCH Effect Test}

Based on the formula (1) and (2) as below, we use the methods of LM test (Engle, 1982) and F test (Tsay, 2004) to test the conditionally heteroskedasticity phenomenon (Pilbeam \& Langeland, 2015). In Table 5, the results of the ARCH effect test show that the two markets have the conditionally heteroskedasticity phenomenon exists. This result suggests that we can use the GARCH model to match and analyze it.

Table 3. Unit root test of ADF and KSS for the return data

\begin{tabular}{ccccc}
\hline ADF & RTWER & REUER & RJER & RSIER \\
\hline Statistic & $-9.352^{* * *}$ & $-48.657^{* * *}$ & $-12.192^{* * * *}$ & $-11.717^{* * *}$ \\
Critical value & $-3.962^{* *}$ & -3.412 & $-3.128^{2}$ & \\
Significant level & $\alpha=1 \%$ & $\alpha=5 \%$ & $\alpha=10 \%$ & RSIER $^{* * *}$ \\
KSS & RTWER & REUER & RJER & $-22.892^{* * * * *}$
\end{tabular}


Critical value $-2.82$

$-2.22$

$-1.92$

Significant level

$\alpha=1 \%$

$\alpha=5 \%$

$\alpha=10 \%$

Notes: ${ }^{* * *}$ denote significance at the level $1 \%$.

Table 4. Co-integration test ( VAR LAG=5)

\begin{tabular}{ccc}
\hline$H_{0}$ & $\lambda_{\max }$ & Critical value \\
\hline None & 17.2930 & 32.1183 \\
At most 1 & 14.7157 & 25.8232 \\
At most 2 & 5.2270 & 19.3870 \\
At most 3 & 4.2138 & 12.5180 \\
\hline
\end{tabular}

Notes: The lag of VAR is selected by the AIC rule [5].

The critical value is given under the level $5 \%$.

Table 5. ARCH effect test

\begin{tabular}{ccc}
\hline RTWER & Engle LM test & Tsay F test \\
\hline Statistic & $789.041^{* * * *}$ & $36.771^{* * * *}$ \\
(p-value) & $(0.0000)$ & $(0.0000)$ \\
\hline
\end{tabular}

Notes : ${ }^{* * *}$ denote significance at the level $1 \%$.

\section{Proposed Model}

Based on the European, Japan and the Singapore exchange rate markets can affect the exchange rate volatility of the Taiwan exchange rate market, and the European, Japan, and the Singapore exchange rate markets do have the trade correlations for the Taiwan exchange rate markets. We follow the idea of selfexciting threshold autoregressive (SETAR) model (Tsay, 1989), the idea of double threshold GARCH model (Brooks, 2001), and the ideas of the papers of Engle (2002); Tse and Tusi (2002), and uses the positive and negative values of European, Japan and Singapore exchange rates' volatility rate are as a threshold. After model process selection, in this paper, we may use the asymmetric GARCH (called AGARCH) model to construct the volatility model of Taiwan's exchange rate market, the AGARCH $(1,1)$ model is illustrated as follows:

$$
\begin{aligned}
& \text { RTWER }_{t}=\phi_{10}+\sum_{j=1}^{2}\left(\phi_{j 1} \text { RTWER }_{t-j}+\phi_{j 2} \text { REUER }_{t-j}+\phi_{j 3} \text { RJER }_{t-j}+\phi_{j 4} \text { RSIER }_{t-j}\right)+a_{1, t} \\
& h_{1, t}=\sum_{j=1}^{8} u_{j, t-1}\left(\alpha_{j 0}+\alpha_{j 1} a_{1, t-1}^{2}+\beta_{j 1} h_{1, t-1}\right),
\end{aligned}
$$

c

$u_{1, t}=\left\{\begin{array}{ccc}1 & \text { if } & R E U E R \leq 0, R J E R_{t} \leq 0 ; R S I E R_{t} \leq 0 \\ 0 & \text { if } & \text { others }\end{array}\right.$,

$u_{2, t}=\left\{\begin{array}{ccc}1 & \text { if } & R E U E R \leq 0, R J E R_{t} \leq 0 ; R S I E R_{t}>0 \\ 0, & \text { if } & \text { others }\end{array}\right.$,

$u_{3, t}=\left\{\begin{array}{ccc}1 & \text { if } & R E U E R \leq 0, R^{\prime} J R_{t}>0 ; R S I E R_{t} \leq 0 \\ 0 & \text { if } & \text { others }\end{array}\right.$, 


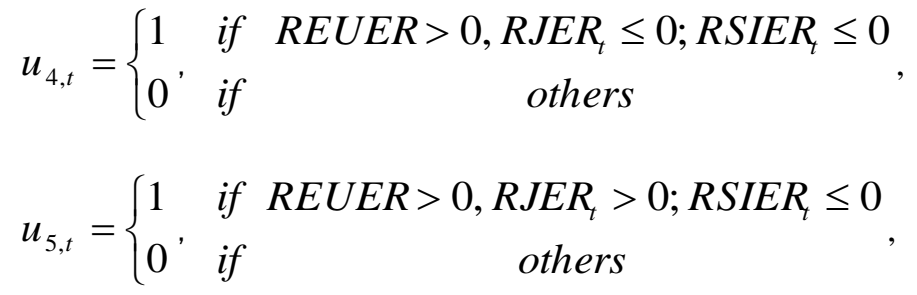

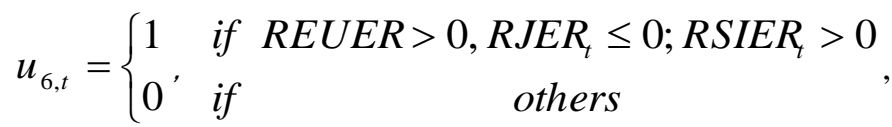

$u_{7, t}=\left\{\begin{array}{llc}1 & \text { if } & R E U E R \leq 0, R_{t} R_{t}>0 ; R_{S I E R}>0 \\ 0 & \text { if } & \text { others }\end{array}\right.$,

$u_{8, t}=\left\{\begin{array}{llc}1 & \text { if } & R E U E R>0, \text { RJER }_{t}>0 ; \text { RSIER }_{t}>0 \\ 0 & \text { if } & \text { others }\end{array}\right.$,

with $R E U E R_{r}>0, R_{E} R_{t}>0$ and RSIER $_{t}>0$ denote good news, REUER $\leq 0, R J E R_{t} \leq 0$ and $R$ SIER $R_{t} \leq 0$ denote bad news. The white noise of $a_{1, t}$ is obeying the Student's t distribution, this is,

$a_{1, t} \sim T_{v}\left(0,(v-2) h_{1, t} / v\right)$

among $v$ is the degree freedom of $a_{1, t}$. The maximum likelihood algorithm method of BHHH (Berndt et. al., 1974) is used to estimate the model's unknown parameters. The programs of RATS and EVIEWS are used in this paper.

\section{Empirical Results}

From the empirical results, we know that Taiwan's exchange rate volatility may be constructed on the AIGARCH $(1,1)$ model. Its estimate result is stated in Table 6.

The empirical results show that the good news and bad news of the European, Japan, and the Singapore exchange rates' volatility will produce the different exchange rates on Taiwan's exchange rate market. And the exchange rate volatilities of the European, Japan, and Singapore also affects the variation risks of the Taiwan exchange rate market.

The Taiwan exchange rate volatility receives before 1 period's impact of the Taiwan exchange rate volatility $\left(\phi_{11}=-0.0860\right)$. The Taiwan exchange rate volatility also receives before 2 period's impact of the European exchange rate volatility $\left(\phi_{12}=0.0628\right.$ and $\phi_{22}=0.0137$ ). The Taiwan exchange rate volatility also receives before 2 period's impact of the Singapore exchange rate volatility $\left(\phi_{14}=0.1343\right.$ and $\left.\phi_{24}=0.0381\right)$.

The Taiwan exchange rate volatility also receives before 1 period's impact of the Japan exchange rate volatility $\left(\phi_{13}=0.0135\right)$. The exchange rate volatility of the European, Japan and the Singapore exchange 
rate markets are also truly influent the exchange rate volatility of the Taiwan exchange rate market. In additional, the estimated value of the degree of freedom for the Student's t distribution is 3.3319, and is significant under the significance level of $0.01(\alpha=1 \%)$. This also demonstrates that this research data has a heavy-tailed distribution.

Table 6. Parameter estimation of the AIGARCH $(1,1)$ model

\begin{tabular}{cccccc}
\hline Parameters & $\phi_{10}$ & $\phi_{11}$ & $\phi_{12}$ & $\phi_{13}$ & $\phi_{14}$ \\
\hline Coefficient & 0.0061 & -0.0860 & 0.0628 & 0.0135 & 0.1343 \\
(p-value) & $(0.0673)$ & $(0.0001)$ & $(0.0000)$ & $(0.0109)$ & $(0.0000)$ \\
Parameters & $\phi_{21}$ & $\phi_{22}$ & $\phi_{23}$ & $\phi_{24}$ & \\
Coefficient & -0.0209 & 0.0137 & 0.0015 & 0.0381 & \\
(p-value) & $(0.2635)$ & $(0.0710)$ & $(0.7765)$ & $(0.0091)$ & \\
Parameters & $\alpha_{10}$ & $\alpha_{11}$ & $\beta_{11}$ & $\alpha_{20}$ & $\alpha_{21}$ \\
Coefficient & 0.0072 & 0.3084 & 0.6916 & 0.0053 & 0.4410 \\
(p-value) & $(0.0056)$ & $(0.0000)$ & $(0.0000)$ & $(0.3288)$ & $(0.0033)$ \\
Parameters & $\beta_{21}$ & $\alpha_{30}$ & $\alpha_{31}$ & $\beta_{31}$ & $\alpha_{40}$ \\
Coefficient & 0.5590 & -0.0002 & 0.2051 & 0.7949 & 0.0133 \\
(p-value) & $(0.0000)$ & $(0.9500)$ & $(0.0029)$ & $(0.0000)$ & $(0.0201)$ \\
Parameters & $\alpha_{41}$ & $\beta_{41}$ & $\alpha_{50}$ & $\alpha_{51}$ & $\beta_{51}$ \\
Coefficient & 0.3915 & 0.6085 & 0.0079 & 0.1122 & 0.8878 \\
(p-value) & $(0.0014)$ & $(0.0000)$ & $(0.0960)$ & $(0.0234)$ & $(0.0000)$ \\
Parameters & $\alpha_{60}$ & $\alpha_{61}$ & $\beta_{61}$ & $\alpha_{70}$ & $\alpha_{71}$ \\
Coefficient & 0.0112 & 0.5620 & 0.4380 & -0.0037 & 0.2894 \\
(p-value) & $(0.0062)$ & $(0.0000)$ & $(0.0000)$ & $(0.3238)$ & $(0.0077)$ \\
Parameters & $\beta_{71}$ & $\alpha_{80}$ & $\alpha_{81}$ & $\beta_{81}$ & $v$ \\
Coefficient & 0.7106 & 0.0070 & 0.3971 & 0.6029 & 3.3319 \\
(p-value) & $(0.0000)$ & $(0.0139)$ & $(0.0000)$ & $(0.0000)$ & $(0.0000)$ \\
\hline
\end{tabular}

Notes p-value $<\alpha$ denotes significance. $(\alpha=1 \%, \alpha=5 \%)$.

From Table 6, the estimated coefficients of the conditional variance equation will produce different variation risks under the bad news and good news of European, Japan and Singapore exchange rate markets. The empirical results show that the Taiwan exchange rate market conforms the conditional supposition of the AIGARCH model. This result also demonstrates the AIGARCH $(1,1)$ model may catch the Taiwan exchange rate volatilities' process. The empirical result shows that the Taiwan exchange rate market has a fixed variation risk under the $R E U E R_{t} \leq 0$ (bad news), the $R J E R_{t} \leq 0$ (bad news) and $R S I E R_{t} \leq 0$ (bad news). The Taiwan exchange rate market has also the fixed variation risk under the $R E U E R>0$ (good news), the $R J E R_{t}>0$ (good news) and $R S I E R_{r}>0$ (good news).

Besides, under the REUER $>0$ (good news), the $R J E R_{t} \leq 0$ (bad news) and $R S I E R_{r} \leq 0$ (bad news), the Taiwan exchange rate market has also the fixed variation risk. Under the REUER $>0$ (good news), the $R J E R_{t} \leq 0$ (bad news) and $R S I E R_{r}>0$ (good news), the Taiwan exchange rate market has also the fixed variation risk. In Table 6 , the Taiwan exchange rate market does have different conditional variation risks under the good and bad news. 
This result demonstrates that the good news and bad news of the European, Japan and the Singapore exchange rate markets will produce different variation risks on the Taiwan exchange rate market. For example, under the REUER $\leq 0$ (bad news), the $R J E R_{t} \leq 0$ (bad news) and $R S I E R_{r} \leq 0$ (bad news), the empirical result shows that the variation risk of the Taiwan exchange rate market equals $\beta_{11}=0.6916$. Under the REUER $>0$ (good news), the $R J E R_{t}>0$ (good news) and $R S I E R_{t}>0$ (good news), the variation risk of the Taiwan exchange rate market equals $\beta_{81}=0.6029$. Under the $R E U E R_{\gamma}>0$ (good news), the $R J E R_{t}>0$ (good news) and $R S I E R_{t} \leq 0$ (bad news), the variation risk of the Taiwan exchange rate market is the highest $\left(\beta_{51}=0.8878\right.$ ). Under the REUER $>0$ (good news), the $R J E R_{t} \leq 0$ (bad news) and $R S I E R_{r}>0$ (good news), the variation risk of the Taiwan exchange rate market is the lowest $\left(\beta_{61}=0.4380\right)$. Therefore, the explanatory ability of the student $t$ distribution and the $\operatorname{AIGARCH}(1,1)$ model is better than the traditional model of the GARCH $(1,1)$.

To test the inappropriateness of the AIGARCH $(1,1)$ model, the test method of Ljung and Box (1978) is used to examine autocorrelation of the standard residual error. This model does not show an autocorrelation of the standard residual error. Therefore, the $\operatorname{AIGARCH}(1,1)$ model are more appropriate.

\section{Asymmetric Test of the AIGARCH(1, 1) Model}

The $\operatorname{AIGARCH}(1,1)$ model is proposed as above. The asymmetric test methods [6] are used the following four methods as sign test, negative size bias test, positive size bias test and joint test. By the sign test, the negative size bias test, the positive size bias test and the joint test show that the Taiwan exchange rate market does not have the asymmetrical effect in Table 7.

Table 7. Asymmetric test of the AIGARCH( 1,1$)$ model

\begin{tabular}{ccc}
\hline RTWER & Sign test & Negative size bias test \\
\hline F statistic & 2.4123 & 0.0007 \\
(p-value) & $(0.1205)$ & $(0.9791)$ \\
RTWER & Positive size bias test & Joint test \\
F statistic & 1.4280 & 1.3274 \\
(p-value) & $(0.2322)$ & $(0.2637)$ \\
\hline
\end{tabular}

Notes: p-value $<\alpha$ denote significance. $(\alpha=5 \%)$.

\section{Conclusions}

The empirical results show that the Taiwan exchange rate markets' volatility does have an asymmetric effect. The Taiwan exchange rate market volatility may construct in the AIGARCH $(1,1)$ model with a positive and negative threshold of European, Japan and Singapore exchange rate volatilities.

The good and bad news of European, Japan and Singapore exchange rate markets affects the exchange rate volatility of the Taiwan exchange rate market. For example, under the REUER $>0$ (good news), the $R J E R_{t}>0$ (good news) and $R S I E R_{r} \leq 0$ (bad news), the variation risk of the Taiwan exchange rate market is the highest $\left(\beta_{51}=0.8878\right)$.

Under the $R E U E R_{r}>0$ (good news), the $R J E R_{t} \leq 0$ (bad news) and $R S I E R_{r}>0$ (good news), the variation risk of the Taiwan exchange rate market is the lowest $\left(\beta_{61}=0.4380\right)$. The empirical result shows that the variation risk of the Taiwan exchange rate market receives the influence of others exchange rate markets. 


\section{References}

Akaike, H. (1998). Information theory and an extension of the maximum likelihood principle. In Selected papers of hirotugu akaike (pp. 199-213). Springer, New York, NY.

Berndt, E. R., Hall, B. H., Hall, R. E., \& Hausman, J. A. (1974). Estimation and inference in nonlinear structural models. In Annals of Economic and Social Measurement, 3(4), 653-665

Brooks, C. (2001). A double-threshold GARCH model for the French Franc / Deutschmark exchange rate. Journal of Forecasting, 20, 135-143.

Dickey, D. A. \& Fuller, W. A. (1981). Likelihood ratio statistic for autoregressive time series with a unit Root. Econometrics, 49, 1057-1072.

Dickey, D.A. \& Fuller, W. A. (1979). Distribution of the estimators for autoregressive time series with a unit Root. Journal of the American Statistical Association, 74, 427-431.

Engle, R. F. \& Ng, V. K. (1993). Measuring and testing the impact of news on volatility. Journal of Finance, 48(5), 1749-1777.

Engle, R. F. (1982). Autoregressive conditional heteroskedasticity with estimates of the variance of United Kingdom Inflation. Econometrica, 50, 987-1007.

Engle, R.F. (2002). Dynamic conditional correlation- a simple class of multivariate GARCH models. Journal of Business and Economic Statistics, 20, 2002, pp. 339-350.

Johansen, S. (1991). Estimation and Hypothesis Testing of Cointegration Vector in Gaussian Vector Autoregressive Models. Econometrica, 52, 389-402.

Kapetanios, G., Shin, Y., \& Snell, A. (2003). Testing for a unit root in the nonlinear STAR framework. Journal of Econometrics, 112(2), 359-379.

Ljung, G. M. \& Box, G.E.P. (1978). On a measure of lack of fit in time series models. Biometrika, 65(2), 297-303.

Pilbeam, K., \& Langeland, K. N. (2015). Forecasting exchange rate volatility: GARCH models versus implied volatility forecasts. International Economics and Economic Policy, 12(1), 127-142.

Tsay, R. S. (2004). Analysis of Financial Time Series (Vol. 543). John Wiley \& Sons.

Tsay, R. S. (1989). Testing and modeling threshold autoregressive processes. Journal of The American Statistical Association, 84(405), 231-240.

Tse, Y. K., \& Tsui, A. K. (2001). A multivariate GARCH model with time-varying correlations. Journal of Business \& Economic Statistics, 20, 351-362. 